\title{
An In-Vitro Study of Irradiated Vitreo-Retinal Membranes
}

\author{
U. CHAKRAVARTHY, D. McCORMICK, C. J. F. MAGUIRE and D. B. ARCHER \\ Belfast
}

\begin{abstract}
Summary
Standard perforating injuries were created in the right eye of 30 rabbits. Twenty of these had the site of injury irradiated using the radioactive ophthalmic ${ }^{60} \mathrm{Cobalt}$ applicator. Vitreo-retinal membranes obtained from non-irradiated and irradiated eyes were propagated in vitro. The morphology and viability of the cells that grew as a monolayer was studied using phase, light and electron microscopy. The proportions of the different cell types that constituted the monolayer was determined using immunofluorescent staining techniques. Non-irradiated membranes elaborated an abundant outgrowth of healthy cells that were predominantly fibroblasts. Irradiated membranes developed a sparse outgrowth of cells with vacuolated cytoplasm and pyknotic nuclei indicating cell destruction. The majority of the surviving cells were glial, with fibroblasts and retinal pigment epithelial cells forming the remainder.
\end{abstract}

Cellular proliferations which form membranes on the surface of the retina and in the vitreous gel occur as a result of a variety of conditions, notably perforating trauma, retinal detachment and diabetes. ${ }^{1}$ The subsequent contraction of such vitreo-retinal membranes may result in retinal detachment and visual loss. ${ }^{2}$ Vitreo-retinal membranes can be induced in the experimental animal by the creation of a standard perforating injury in the posterior segment of the eye. ${ }^{3}$ We have shown that the irradiation of the site of the standard perforating injury in the experimental animal causes the formation of a hypocellular attenuated membrane or atrophic scar. ${ }^{4}$ The irradiated attenuated vitreoretinal membranes exert minimal or no tractional forces, unlike the membranes that occur in non-irradiated eyes. As the contractile property of such membranes is thought to be due to the presence of myofibroblasts, ${ }^{5}$ we compared the cellular viability and the proportions of the constituent cells to each other in non-irradiated and irradiated vitreo-retinal membranes using tissue culture techniques. The effect of gamma radiation on cellular morphology, growth and division of diploid normal and tumour cells in tissue culture has been well documented by Puck and others. ${ }^{6,7}$ However, to our knowledge there has never been an examination in tissue culture of non-tumour tissue that has been irradiated in vivo.

\footnotetext{
Materials and Methods

Perforating injuries were created in the right eye of each of a group of 30 pigmented rabbits. The site of injury in 20 of these rabbits was irradiated using an ophthalmic ${ }^{60} \mathrm{Cobalt}$ applicator. The applicator was sutured directly onto the injured sclera over the site
} 
of perforation and was left in position for 48 hours. During this time a dose of approximately $100 \mathrm{~Gy}$ was delivered to the tissues within a depth of $1 \mathrm{~mm}$ from the plaque with progressively decreasing doses to tissues at a greater depth from the plaque. Details of the technique used to create the injury, apply the plaque and calculate the dose of radiation delivered to the tissues underlying the plaque have been described in a previous publication. ${ }^{4}$ The rabbits were sacrificed three weeks after injury and the right eyes enucleated. The anterior segment of the globe was excised and the lens removed. The site of perforation was inspected and if a vitreo-retinal membrane was present it was carefully dissected away from the retina and placed in RPM1 1640 tissue culture medium containing penicillin and streptomycin, and $15 \%$ foetal calf serum. Each membrane was explanted into a $25 \mathrm{ml}$ Falcon flask and held in position by a glass coverslip fixed with wax. Five mls of fresh tissue culture medium was used to cover the explant and the flasks were incubated at $37^{\circ} \mathrm{C}$ in an atmosphere of $95 \%$ air and $5 \%$ $\mathrm{CO} 2$. The medium in the flasks was changed once weekly and the explants were observed daily. The glass coverslip with its adherent primary monolayer of cells if any, was removed at four weeks for immunocytochemical studies. The cells that were left behind in the parent flask were incubated with medium for a further six to 12 weeks and subcultured onto glass coverslips.

\section{Immunocytochemistry}

The glass coverslips with the attached cellular monolayer were placed in acetone, cooled to $4^{\circ} \mathrm{C}$ for 20 minutes and air dried at room temperature for one hour. The coverslips were incubated with rabbit immunoglobulin (Dako) in order to minimise non-specific staining. The cells were exposed to monoclonal anti-vimentin antibody (Labsystems) raised in the mouse, for 30 mins. at room temperature. Anti-mouse immunoglobulin fluorescein isothiocyanate conjugate (IgG/FITC) obtained from Dako Laboratories was then used to demonstrate the primary antibody. The cells were next exposed to anti glial fibrillary acidic protein (GFAP) antibody (from our own laboratory) raised in the rabbit, for 30 mins. at room temperature. Anti-rabbit immunoglobulin rhodamine isothiocyanate conjugate (IgG/RITC Sigma) was then used to demonstrate the primary antibody. Between antibody changes the coverslips were thoroughly washed with phosphate buffered saline (PBS). The coverslips were mounted with $50 \%$ glycerol onto glass slides and examined under a Leitz fluorescence microscope.

\section{Light Microscopy}

Monolayers of cells grown on glass coverslips obtained from the first subculture were fixed in $10 \%$ formalin and then dehydrated through ascending concentrations of alcohol and stained with Haematoxylin and Eosin, Masson trichrome and Phospho-tungstic acid stains.

\section{Electron Microscopy}

The primary outgrowth that was left behind in some of the parent flasks was fixed in 5\% gluteraldehyde, washed in phosphate buffer, dehydrated and infiltrated with resin which was allowed to polymerise at $60^{\circ} \mathrm{C}$ for 24 hours. The top of the flask was then sawn off and the base of the flask was removed from the resin layer which separated in pieces. The pieces were then glued onto resin blanks and sectioned on an ultramicrotome. After staining with uranyl acetate and lead citrate the grids were examined on the Phillips transmission electron microscope.

\section{Results}

At three weeks all 10 non-irradiated rabbit eyes developed vitreo-retinal membranes. These membranes extended from the site of perforation into the eye along the surface of the retina adjacent to the wound and proliferated into the vitreous. Eleven of the 20 irradiated globes had a flat atrophic sclero-chorioretinal scar without a vitreo-retinal membrane. The remaining 9 of the 20 irradiated eyes exhibited membrane formation but the membranes were attenuated and gained no attachment to other intraocular structure (Table I).

\section{Non-Irradiated explants}

Cellular migration from 6 of the 10 explants was evident as early as 48 hours after setting up the cultures. Three demonstrated cell migration and division within 5 days of explanation and one explant showed no growth 12 weeks after explantation. The cells that emerged from the explanted tissue migrated freely and by day 10 all 9 growing explants had elaborated several colonies of cells (Fig. 1). A confluent monolayer was present in all but one flask by three weeks. The cells were spindle shaped orientating themselves parallel to each other forming the swirling patterns that are characteristic of fibroblasts. They were uniform in size and 
Table I Comparison of Results Obtained from the Culture of Non-Irradiated and Irradiated Explants

\begin{tabular}{lcc}
\hline & Non-Irradiated & Irradiated \\
\hline No. of Rabbits in Study & 10 & 20 \\
No. of Eyes with Membranes that could be Explanted & 10 & 9 \\
No. of Successful Explants & 9 & 6 \\
First Appearance of Cells & 3.3 days & 5.0 days \\
First Appearance of Giant Cells & 5.3 weeks & 1.8 weeks \\
Confluent Growth Achieved in & 9 & 3 \\
\hline
\end{tabular}

shape, and in general had a single nucleus although a few bi-nucleate cells were present (Fig. 2). When the monolayer reached the edge of the glass coverslip the cells migrated and attached to the plastic base of the Falcon flask. After four weeks a few multinucleate giant cells were present in the monolayer and the medium contained some free floating refractile cells. However, the edge of the confluent outgrowth showed healthy spreading cells (Fig. 3). At 12 weeks the cells formed an extensive monolayer on the base of the T25 flask, appeared healthy and subcultured easily onto glass coverslips.

Immunofluorescent staining of the coverslips removed 4 weeks after setting up the explants showed that the vast majority of cells $(90 \%)$ were vimentin positive and GFAP negative (Fig. 4). A few cells were GFAP and vimentin positive while a small population of cells were both GFAP and vimentin negative.

On electron microscopy the majority of cells had large bundles of myofilaments in their cytoplasm and abundant rough-surfaced endoplasmic reticulum. The cells had large ovoid nuclei with several indentations. Many electron dense areas were present, located along the bundles of myofilaments and beneath the plasmalemma.

\section{Irradiated Explants}

Cellular migration from four of the irradiated

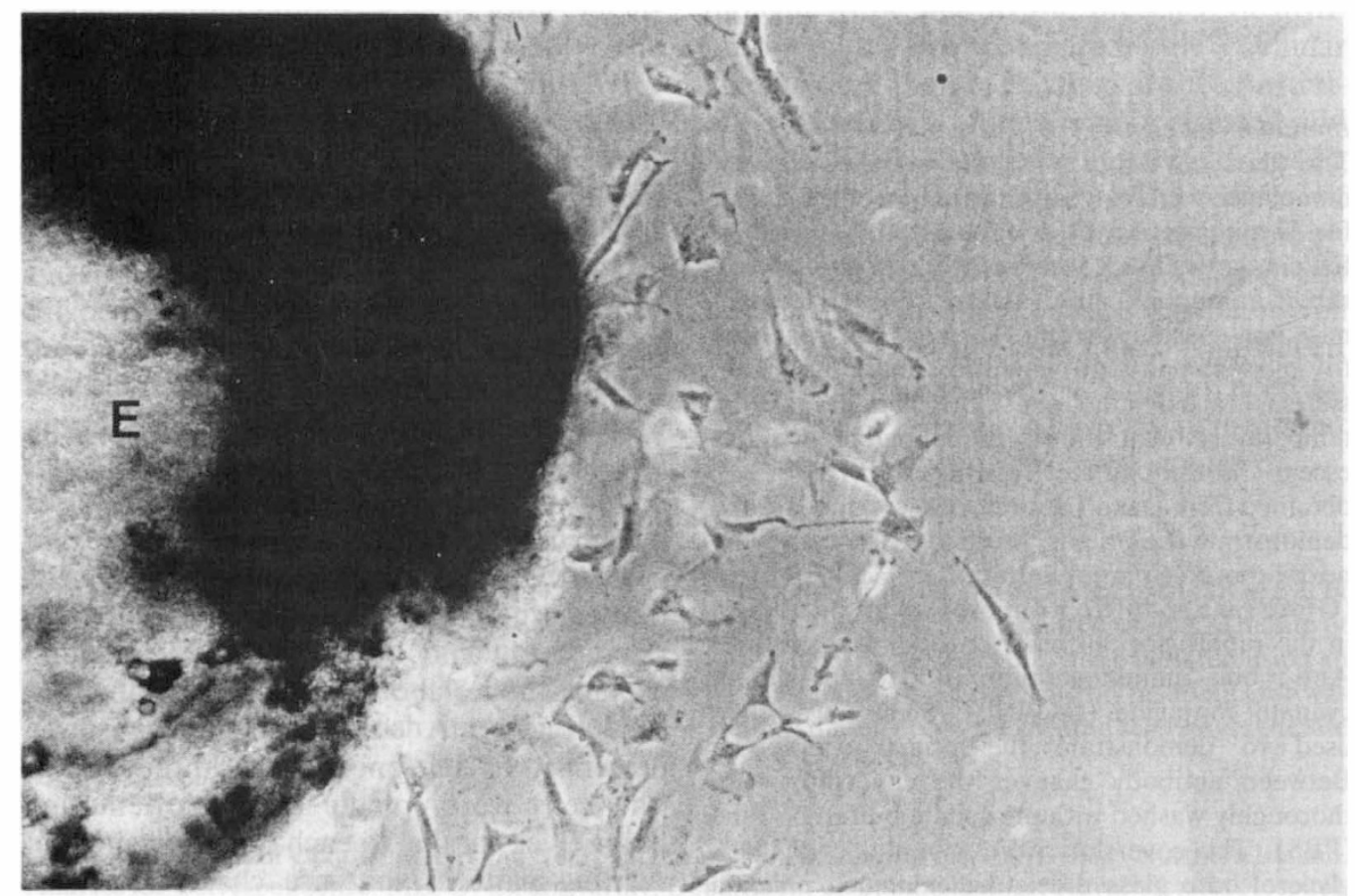

Fig. 1. Non-irradiated explant $(E)$ with growing colony of cells. Final magnification $\times 180$. 


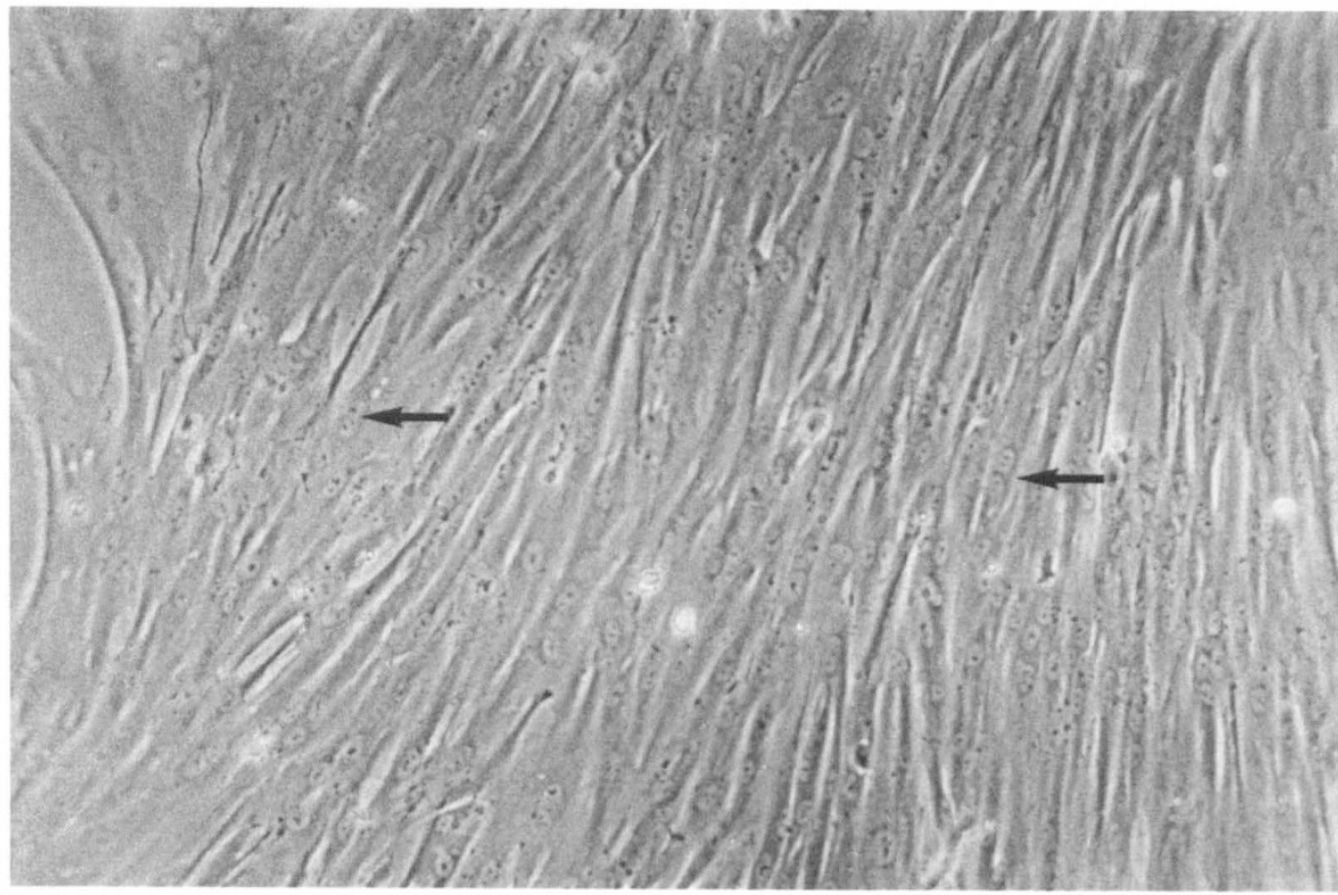

Fig. 2. Confluent monolayer of uniform spindle shaped cells elaborated by non-irradiated explant. Note binucleate cells (arrows). Final magnification $\times 180$.

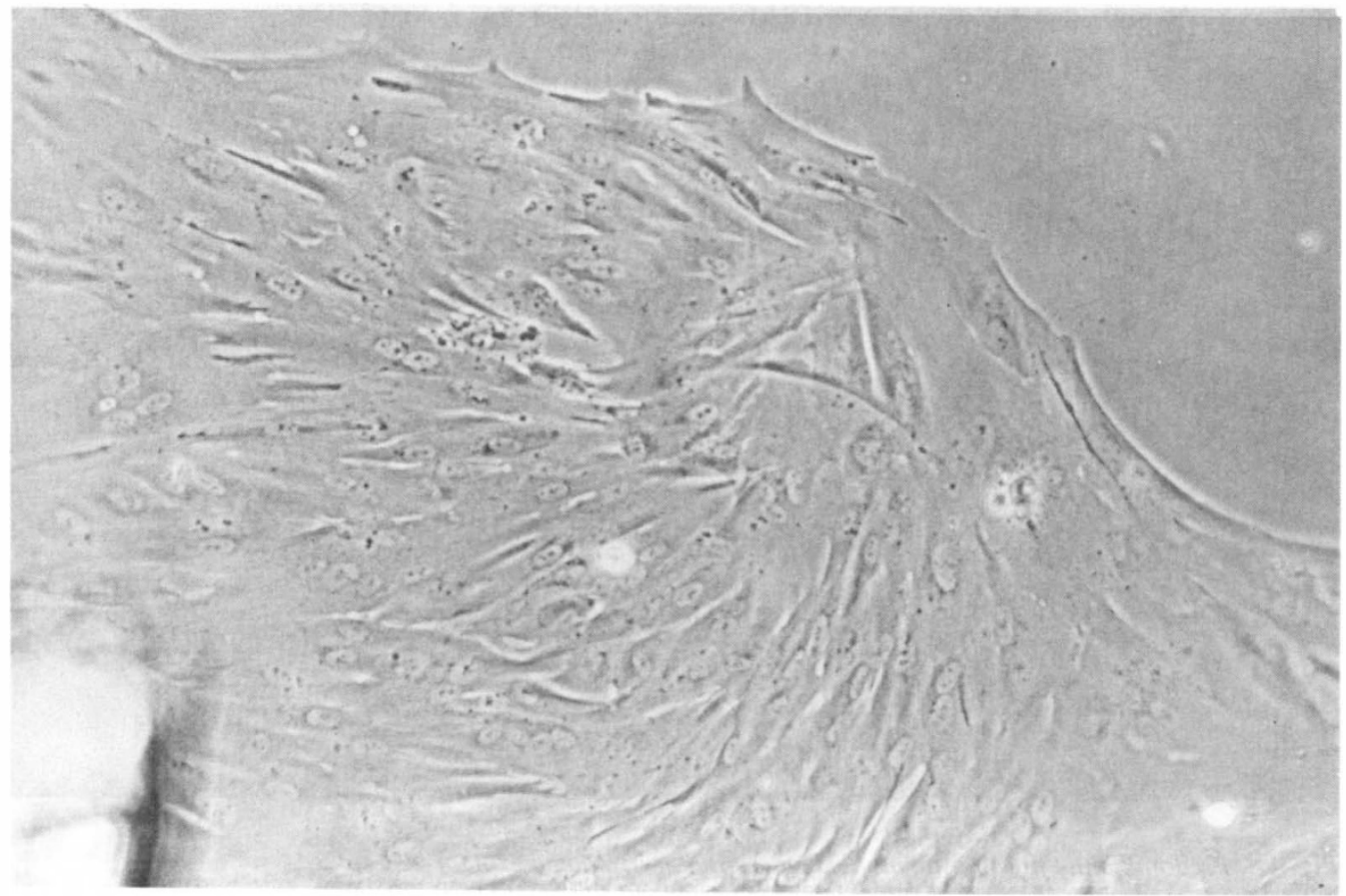

Fig. 3. Edge of confluent advancing monolayer from a non-irradiated explant. Final magnification $\times 180$. 


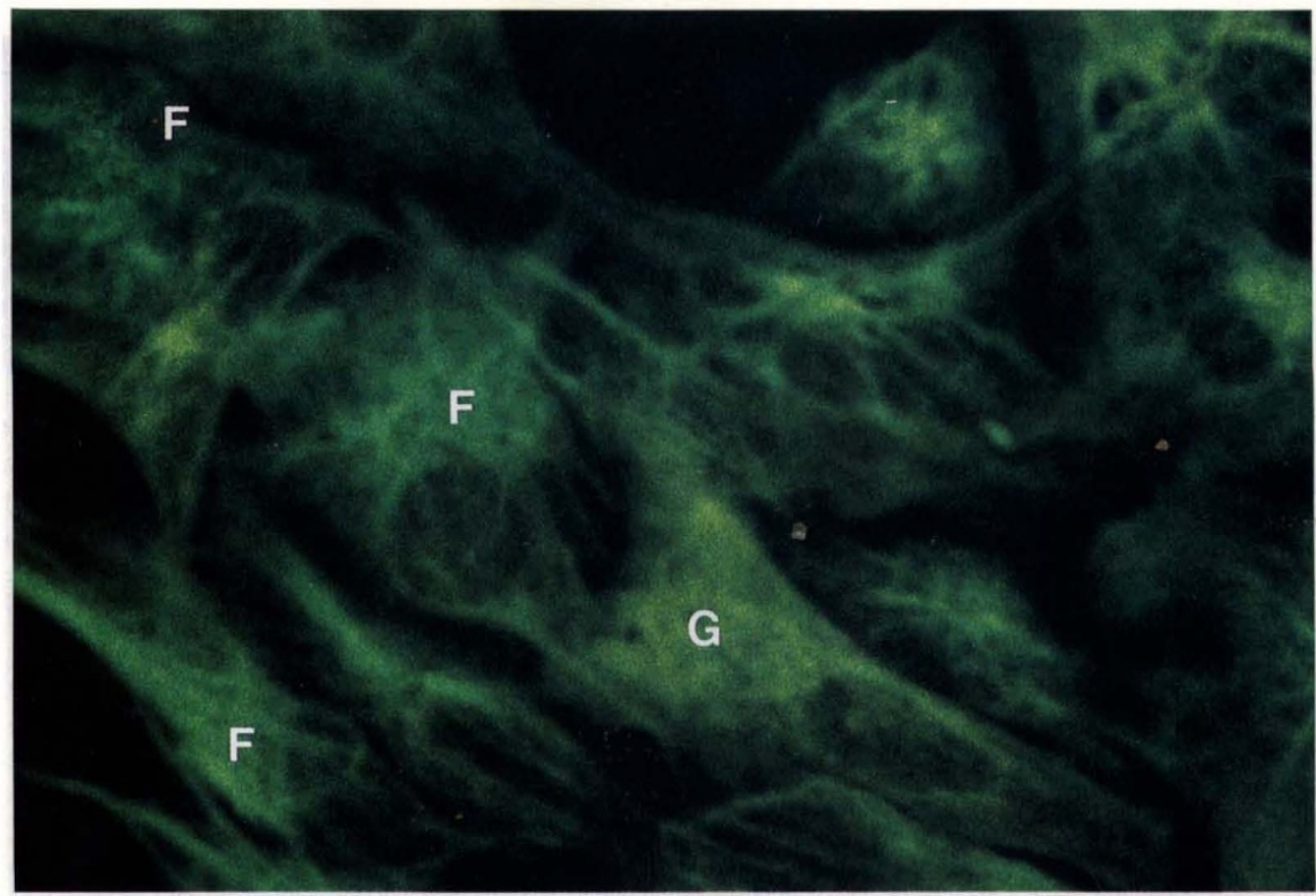

(a)

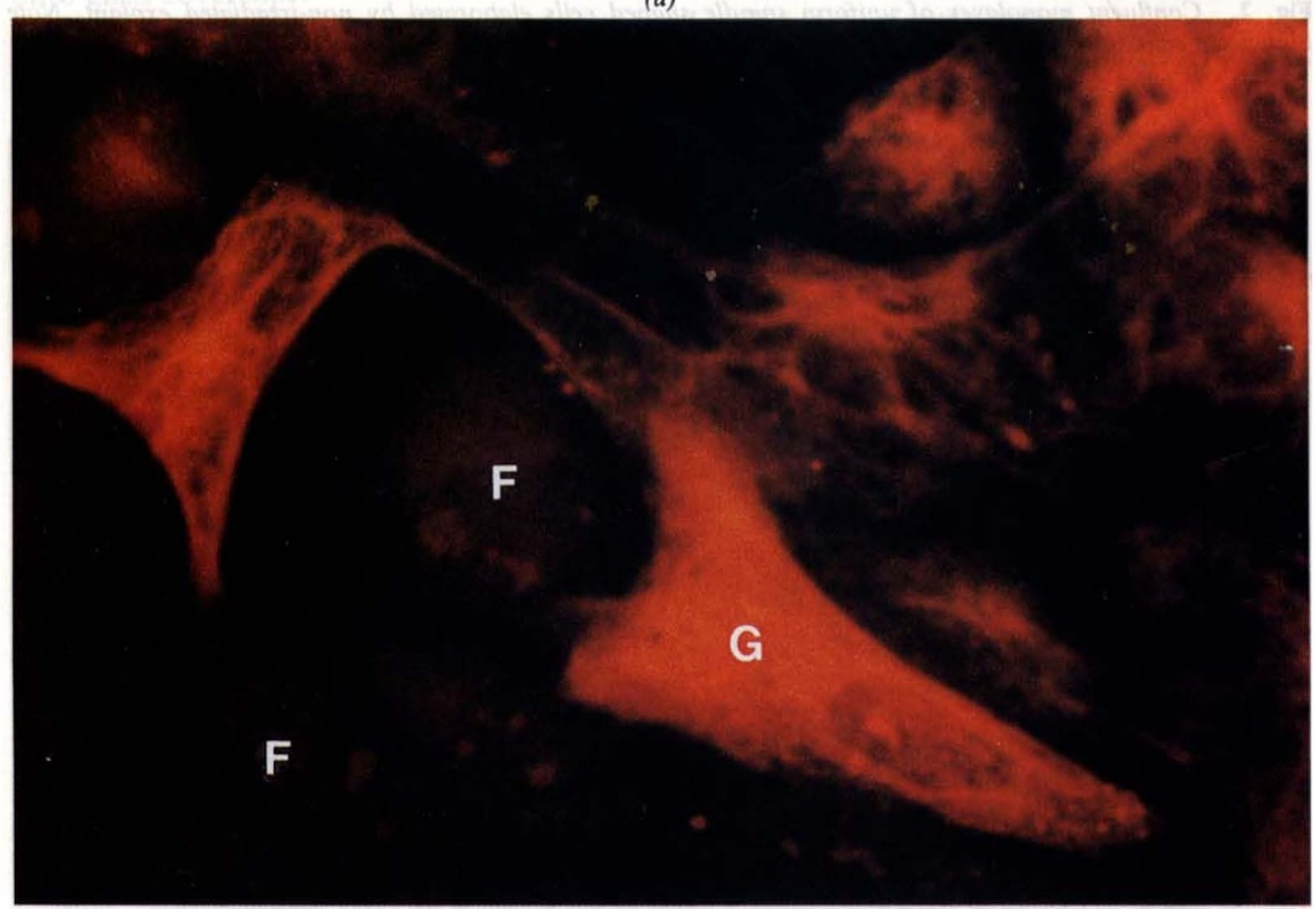

Fig. 4. Predominantly fibroblastic monolayer from non-irradiated explant.

(a) most cells $(F)$ show the fluorescence to vimentin (1 gG/FITC)

(b) few cells $(G)$ show the fluorescence to GFAP (1 gG/RITC) 


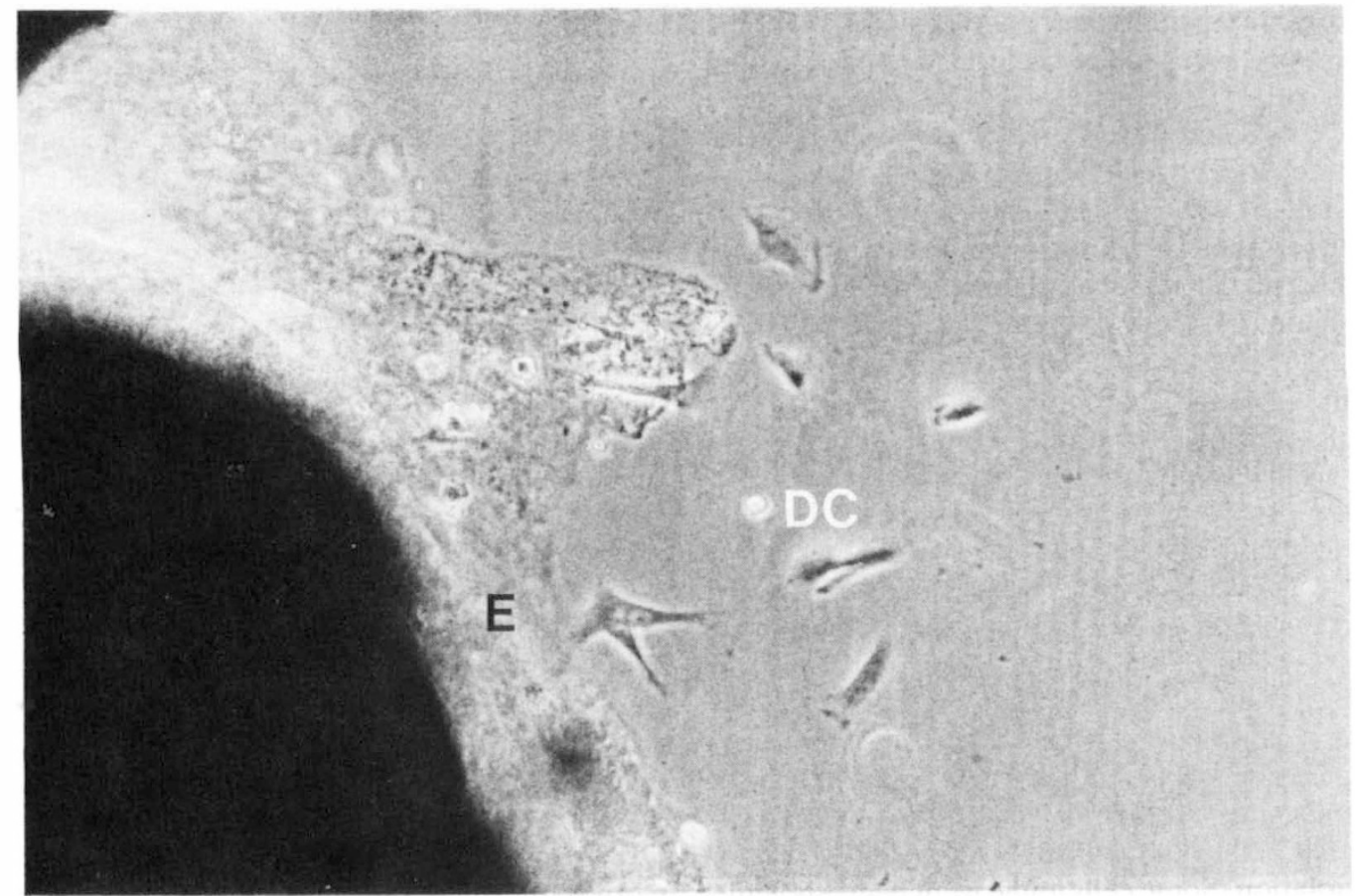

Fig. 5. Irradiated explant (E) with sparse cellular outgrowth. (DC) Detached non-viable cell. Final magnification $\times 180$.

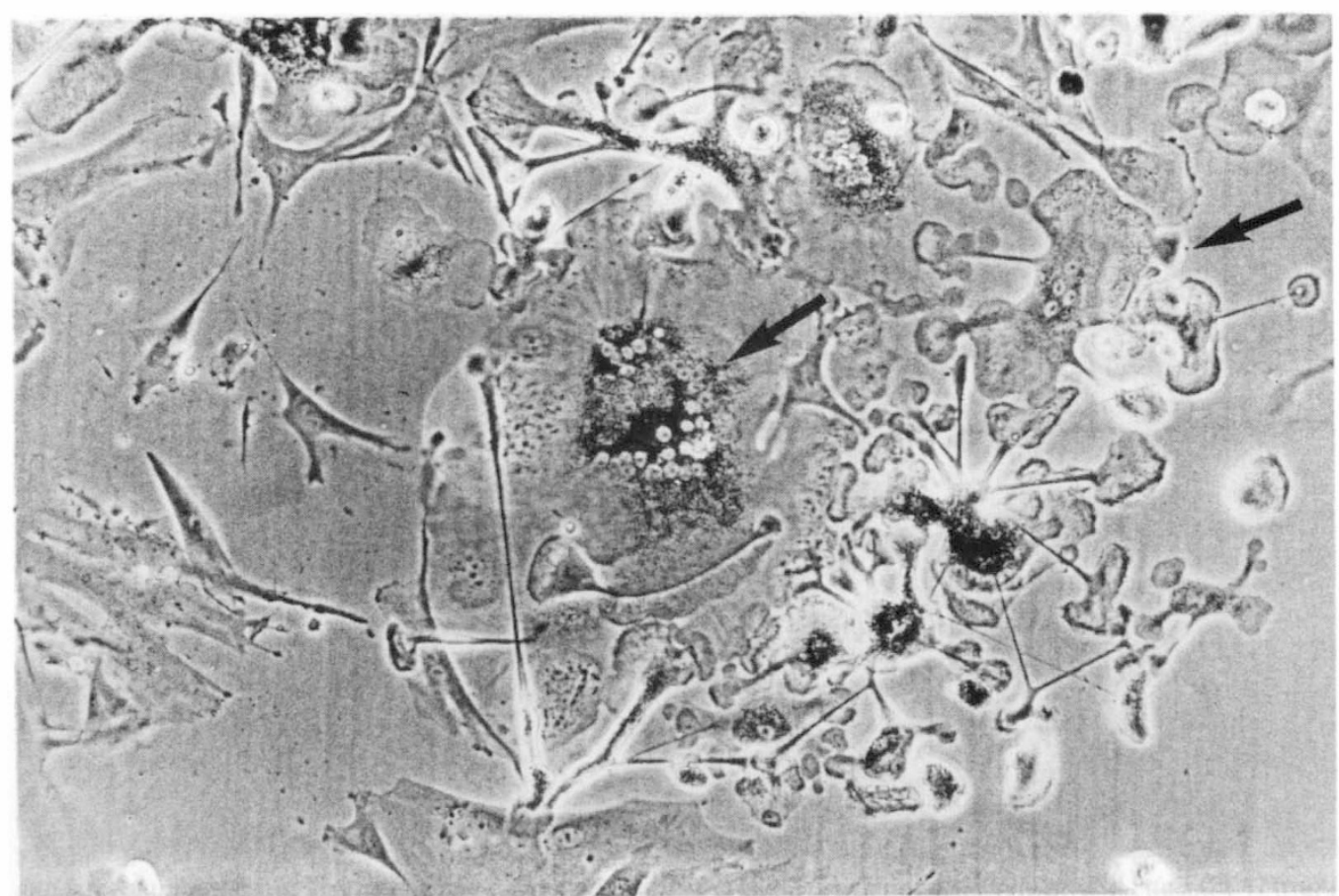

Fig. 6. Abnormal cells from irradiated explant. Note bizarre shapes and multinucleate giant cells (arrows). Final magnification $\times 360$. 
explants commenced at day 5. Two of the explants began to show cell migration and growth between days 5 and 10 , and three explants showed no cell migration even at 12 weeks. The cellular outgrowth was sparse (Fig. 5) and the cells had a highly granular cytoplasm containing many vacuoles. They migrated poorly and clumped together, piling up on top of each other to form colonies close to the explant. The cells were mostly polygonal in shape and many cells assumed bizarre shapes (Fig. 6). Multinucleate giant cells were visible among the earliest of the cells to emerge from the explant. Some of the cells detached and floated off into the medium, becoming rounded, refractile and wrinkled. After three weeks there was sufficient outgrowth of cells to form a semi-confluent layer, but at this stage the cells had failed to reach the perimeter of the coverslip. Confluent areas were present in $30 \%$ of flasks bearing irradiated explants at 4 weeks, although many cells had pyknotic nuclei and cytoplasmic vacuolation. Some cells underwent necrosis while still attached to the plastic of the flask, and after the cell had disappeared characteristic fragments of cell substance could be seen still adherent to the flask (Fig. 7). Giant cells were present in large numbers throughout the outgrowth. At 12 weeks the cells at the edge of the monolayer continued to divide and spread but many demonstrated large lysosomal vacuoles indicating imminent cell death. Immunofluorescent staining revealed that more than half the cells $(65 \%)$ were GFAP and vimentin positive (Fig. 8). Approximately $20 \%$ were positive for vimentin alone and the remaining cells $(15 \%)$ were both vimentin and GFAP negative. Immunofluorescent staining in most of the irradiated cells was poor. Twelve weeks from explanation up to $60 \%$ of the cells that remained were either dead or dying and attempts to subculture the cells from the irradiated explants were generally unsuccessful. On light microscopy the cells that survived subculturing were pleomorphic, often multinucleate and had extensive cytoplasmic vacuolation. Electron microscopy confirmed the glial identity of these cells.

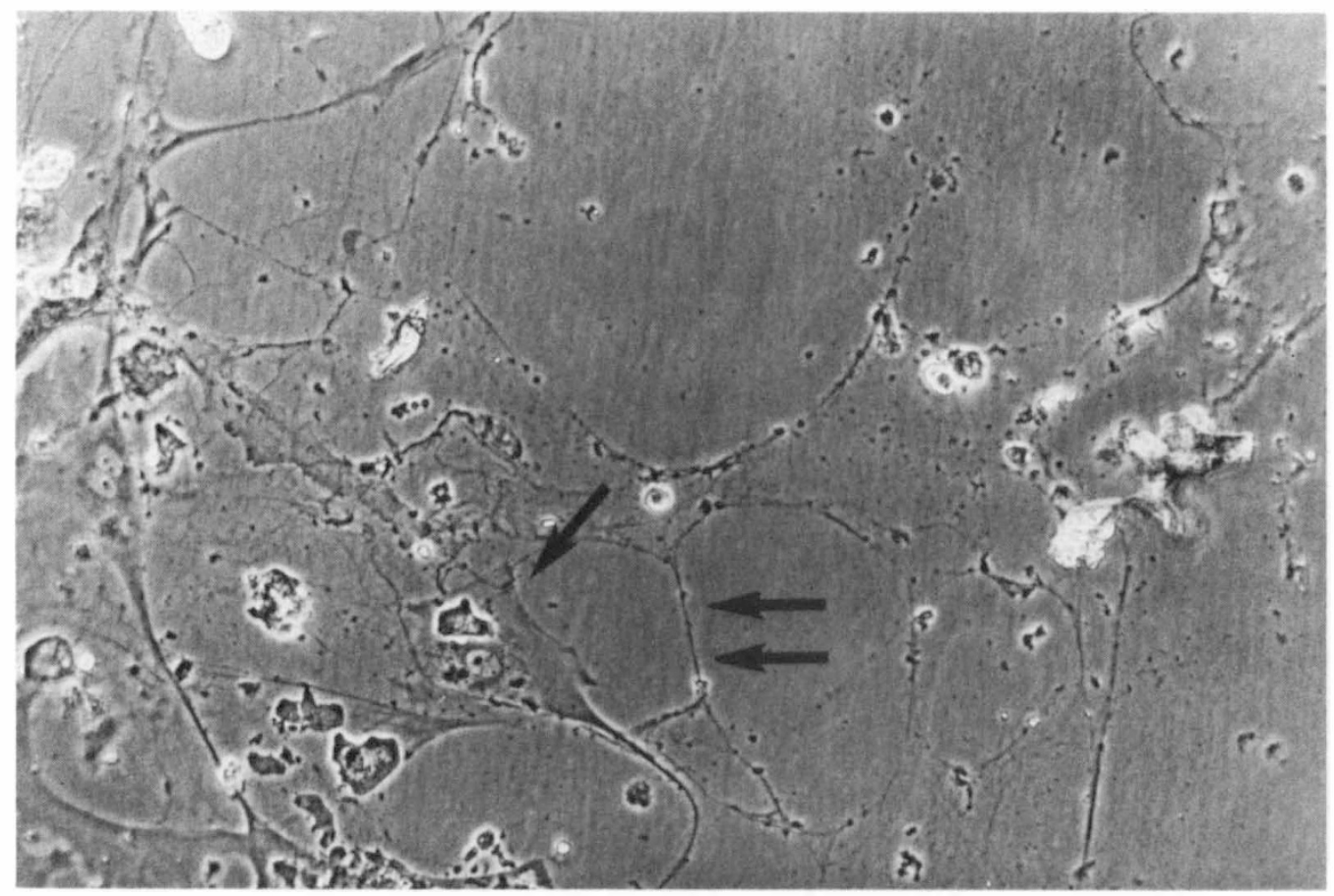

Fig. 7. Edge of outgrowth from irradiated explant. Cells with vacuolated cytoplasm and pyknotic nuclei (arrow). Some cells have undergone disintegration while still attached to the flask and the outlines of these ghost cells can be seen (double arrow). Final magnification $\times 360$. 


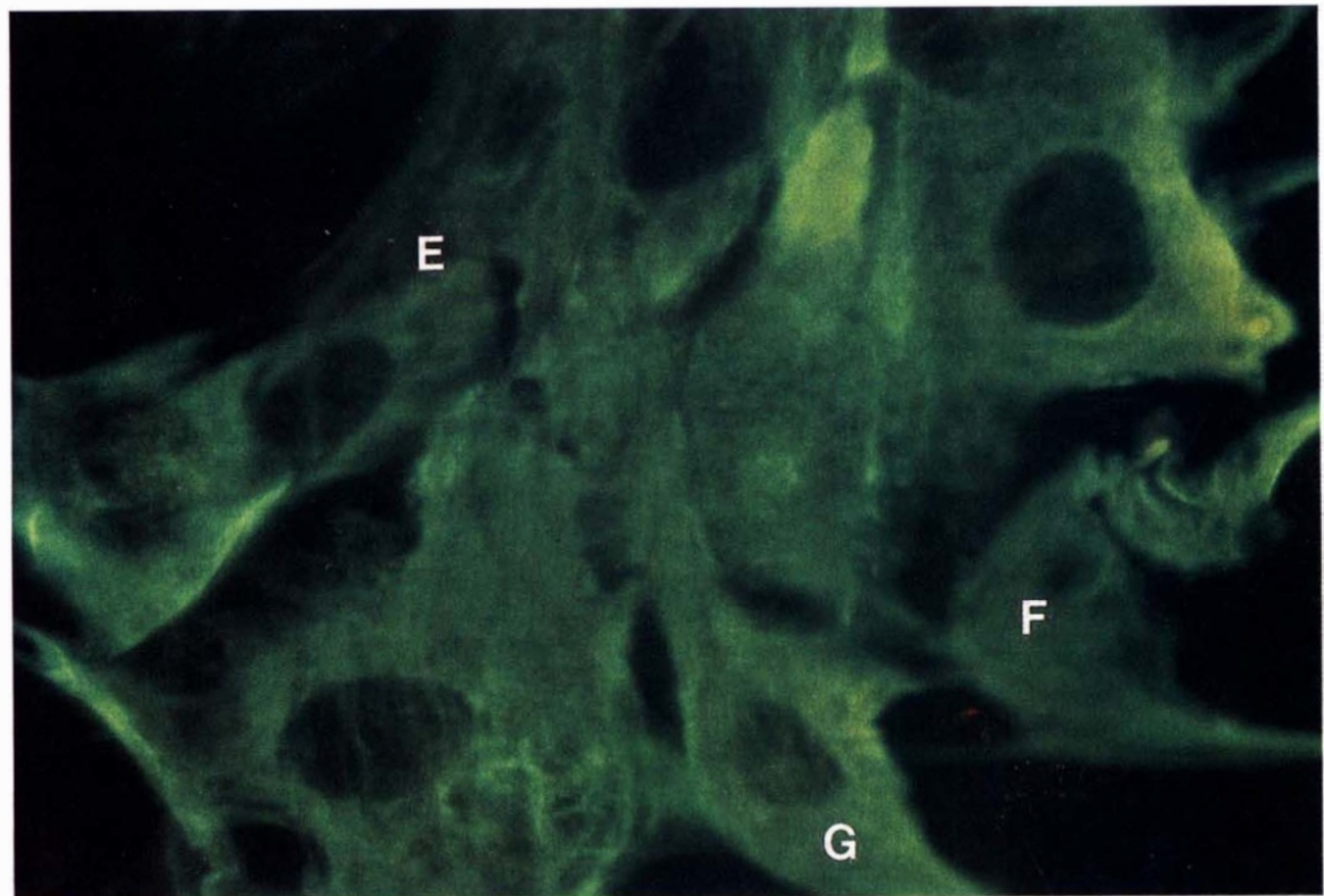

FIG. 8

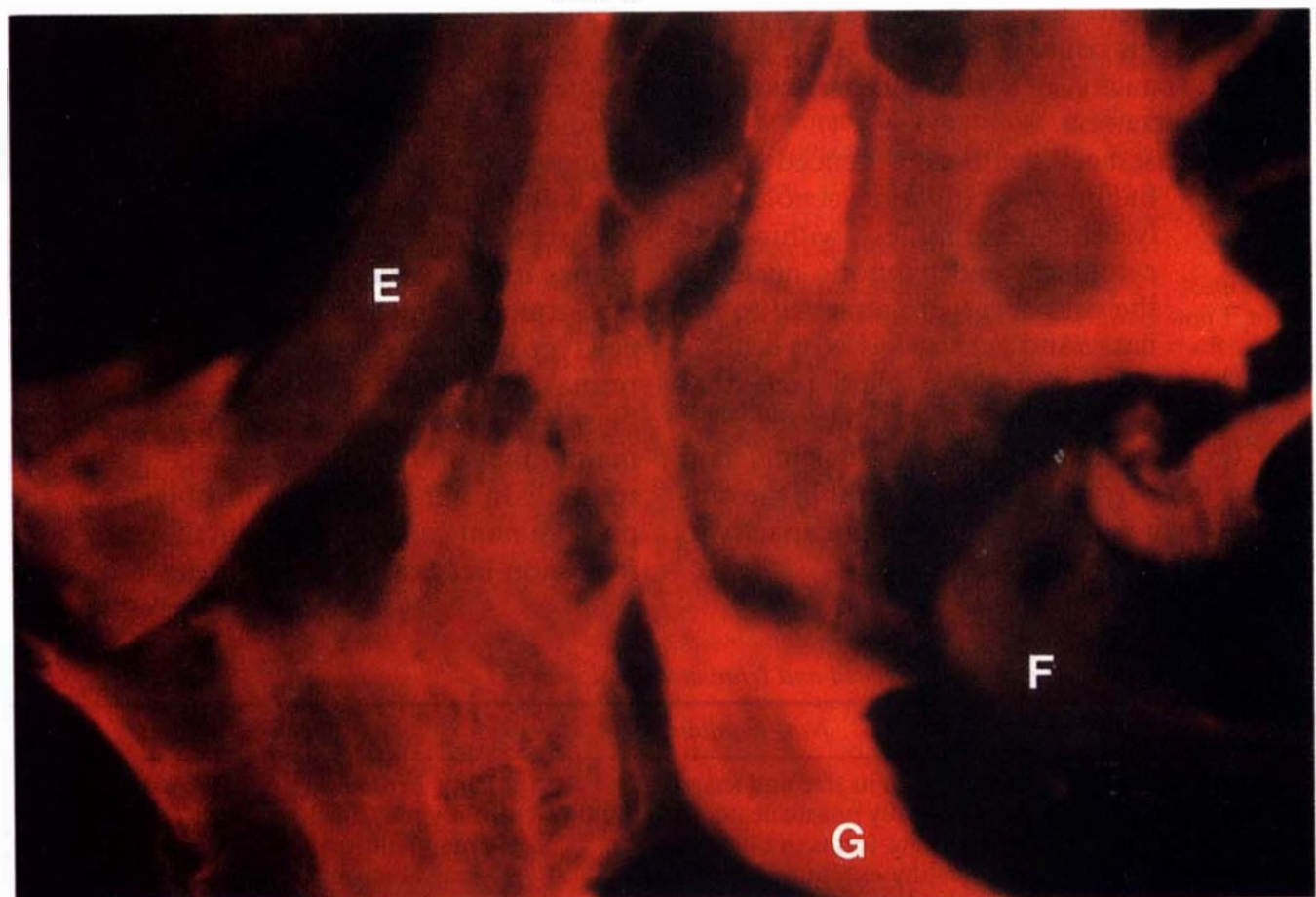

Fig. 8(a \& b). Immunofluorescent staining of cells obtained from an irradiated explant. The cells are enlarged and irregular in outline. The intermediate filaments of most cells $(G)$ stain to both vimentin $(8 A)$ and $G F A P(8 B)$ indicating glial origin of cells. $(F)$ Fibroblast + to vimentin only. (EC) Cell negative to both vimentin and GFAP of probable retinal pigment epithelial origin. 


\section{Discussion}

Detailed studies by Puck et al on gamma irradiation of cells when they have been grown as a monolayer in tissue culture, have shown that the genetic apparatus is damaged. ${ }^{6}$ This results in cessation of division after 3 to 4 mitotic divisions, and this behaviour indicates that although the physiological apparatus can maintain cell viability the cell cannot provide an indefinitely self-sustaining replication owing to the destruction by irradiation of some essential element in the reproductive cycle. ${ }^{6} \mathrm{X}$-irradiation giant cells develop and these cells are enlarged due to growth without replication. ${ }^{8}$

The differences between non-irradiated and irradiated explants are summarised in Tables I and II. The cells which grew out of the irradiated explants in our study showed all the characteristics of radiation damage as described by Puck. ${ }^{6}$ The density of the cellular outgrowth was greatly reduced by comparison with the outgrowth from non-irradiated membranes, and irradiated explants reached confluence much later than non-irradiated cultures. This could be due to:

(i) the paucity of cells within irradiated membranes ${ }^{9}$

(ii) increased cell death as evidenced by

(a) the presence of large vacuoles and lysosomal granules within the cytoplasm and pyknotic nuclei in the cells that were attached to the flask, and

(b) many refractile round cells that were adrift in the medium.

(iii) the large numbers of multinucleate giant cells ( $\mathrm{x}$-irradiation giants) within the outgrowth which have lost their capacity to divide.
Tolmach showed that $\mathrm{X}$-irradiation giant cells are present within 12 days of irradiating a culture and form a fairly stable population although they cannot replicate. ${ }^{8}$ In our study, giant cells were among the earliest cells to appear from the irradiated explants and reached maximum density around 3 weeks. It is therefore presumed that such cells had already formed within the explant and then emerged into the monolayer. The appearance of some multinucleate giant forms in longstanding outgrowths from non-irradiated membranes was consistent with the recognised phenomenon of chromosomal aberrations which occurs during repeated mitosis in old cultures.

Normally, cells grown as monolayers in tissue culture migrate freely attaching to the surface of the flask. However, the cells from the irradiated explants migrated poorly, indicating damage to the locomotor apparatus which consists of actin microfilaments in association with other cytoskeletal elements such as microtubules and intermediate filaments. ${ }^{10}$ Evidence of damage to the cytoskeletal system came from our immunofluorescent studies in which the cellular outgrowth from irradiated explants stained poorly due to the fragmentation and destruction of the intermediate filaments.

Hiscott et al. ${ }^{11}$ cultured vitreo-retinal membranes from a variety of conditions including post-traumatic membranes. The predominant cell type in contractile membranes that caused retinal detachment was found to be the fibroblast. Where glial cells alone were present the membranes did not exert traction on the retina. ${ }^{11}$ In our study the fibroblast was the predominant cell type found in the outgrowth from non-irradiated membranes which were

Table II Comparison of Non-Irradiated and Irradiated Explants

\begin{tabular}{lll}
\hline & \multicolumn{1}{c}{ Non-Irradiated } & \multicolumn{1}{c}{ Irradiated } \\
\hline $\begin{array}{l}\text { Cell Morphology } \\
\text { Number of Nuclei }\end{array}$ & $\begin{array}{l}\text { Uniform in size and shape } \\
\text { Generally uni-nucleate. Few multi- } \\
\text { nucleate forms in old cultures }\end{array}$ & $\begin{array}{l}\text { Pleomorphic with bizarre shapes } \\
\text { Many multinucleate giant cells even in } \\
\text { young cultures } \\
\text { State of Cells }\end{array}$ \\
$\begin{array}{l}\text { Healthy except in high density } \\
\text { old cultures }\end{array}$ & $\begin{array}{l}\text { Many abnormal cells with granular } \\
\text { vacuolated cytoplasm, pyknotic nuclei } \\
\text { and a tendency to detach from substrate }\end{array}$ \\
$\begin{array}{ll}\text { Immunocytochemistry } \\
\text { Subculture }\end{array}$ & $\begin{array}{l}\text { Predominantly fibroblastic } \\
\text { Easy (success rate 100\%) }\end{array}$ & Difficult (success rate $30 \%)$ \\
\hline
\end{tabular}


highly contractile. The cells orientated themselves parallel to each other and formed swirling patterns that are characteristic of fibroblasts. On electron microscopy the cells showed all the features of the myofibroblast, the key cell in wound healing with contractile potential. ${ }^{12}$ By contrast the outgrowth from the irradiated non-contractile membranes contained a higher proportion of glial cells than fibroblasts. On phase and light microscopy the glial cells were polygonal and did not form the swirling patterns, nor exhibit a parallel orientation. On electron microscopy the cells had a basement membrane and exhibited several gap junctions.

Fibroblastic cells are extremely radiosensitive owing to their high rate of cell division, corresponding in in vivo radiosensitivity to the

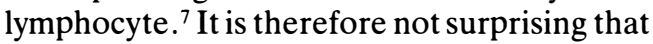
the fibroblast component suffered most destruction following irradiation, allowing the glial cells (and possibly retinal pigment epithelial cells) to proliferate and form a greater proportion of the vitreo-retinal membrane and scar. This perhaps accounts for the fact that wound healing was completed despite irradiation. ${ }^{4}$ The reduction in the contractile property of irradiated membranes is again indicative of the lack of fibroblasts and lends support to the theory that predominantly glial membranes cause minimal or no traction when compared with fibroblastic membranes. ${ }^{11}$ The greater sensitivity of the fibroblast to the lethal effects of gamma radiation therefore indicates its potential as a therapeutic tool in the prevention of contractile vitreo-retinal membranes.

\section{References}

${ }^{1}$ Kampik A, Kenyon KR, Michels RG, et al.: Epiretinal and vitreous membranes. Comparative study of 56 cases. Arch. Ophthalmol. 1981, 99: 1445454.

${ }^{2}$ Machemer R: Pathogenesis and classification of massive periretinal proliferation. $\mathrm{Br} J$ Ophthalmol 1978, 62: 737-47.

${ }^{3}$ Cleary PE and Ryan SJ: Posterior perforating eye injury. Experimental animal model. Trans. Ophthalmol. Soc. U.K. 1978, 98: 34-7.

${ }^{4}$ Chakravarthy U, Maguire CJF and Archer DB: Experimental posterior perforating ocular injury: A controlled study of the gross effects of localised gamma irradiation. $\mathrm{Br} \mathrm{J}$ Ophthalmol. 1986, 70: 561-9.

${ }^{5}$ Cleary PE, Minkler SD and Ryan SJ: Ultrastructure of traction retinal detachment in rhesus monkey eyes after a posterior penetrating ocular injury. Am J Ophthalmol. 1980, 90: 829-45.

${ }^{6}$ Puck TT and Marcus PI: Action of X-rays on mammalian cells. J. Exp. Med. 1956, 103: 653-66.

${ }^{7}$ Puck TT, Morkovin D, Marcus PI and Cieciura SJ: Action of X-rays on mammalian cells. II Survival curves of cells from normal human tissues. $J$. Exp. Med. 1957, 106: 485-500.

8 Tolmach LJ and Marcus PI: Development of X-ray induced giant HeLa cells. Exp. Cell. Res. 1960, 20: $350-60$.

${ }^{9}$ Chakravarthy U, Gardiner TA, Maguire CJF and Archer DB: Localised gamma irradiation and experimental intraocular proliferation. Trans. Ophthalmol. Soc. U.K. 1985, 104: 792-7.

Lazarides, E: Intermediate filaments as mechanical integrators of cellular space. Nature Lond. 1980, 283: $249-56$.

${ }^{11}$ Hiscott PS, Grierson I, Trombetta CT, Rahi AHS, Marshall J and McLeod D: Retinal and Epiretinal glia-an immunohistochemical study. $B r$. J. Ophthalmol. 1984, 68: 698-707.

12 Gabbiani G: The myofibroblast: A key cell for wound healing and fibrocontractive diseases. Progress Clin. Biol. Res. 1981, 54: 183-94. 